\title{
A Preliminary Study on the Distribution Pattern, Feeding Behavior and Invasiveness of the Exotic Fish, Chitala ornata (Clown Knife Fish) in the Sub Water Ways of Attanagalu Oya
}

\author{
Perera G.D.T.* and Weerakoon D. \\ Department of Zoology, University of Colombo, Sri Lanka \\ *thaveesha2002@gmail.com
}

\begin{abstract}
Increasing threat from the introduced invasive species has been identified as one of the major risk factors for the extinction of freshwater fishes. There are number of identified freshwater alien species which have become invasive within Sri Lankan natural waters. However, there is a dearth of information regarding many of these alien invasive species. Therefore, this research project focused on elucidation of distribution pattern, food and feeding habitats and invasiveness of Chitala ornata, an alien invasive freshwater fish species in potentially new site of infestation in the Attanagalu oya and its tributaries over a period of three months as a preliminary study. Key objectives of the study were, to find out the present distribution of $C$. ornata in Attanagalu Oya and its tributaries, to evaluate the food and feeding habits of $C$. ornata through gut analysis and to find out the presence of other invasive/introduced species in the area. Over the study peroid, 50 individuals of $C$. ornata ranging from $21 \mathrm{~cm}$ to $>80 \mathrm{~cm}$ were collected using hook and line fishing gear and captured fish were deep-frozen immediately after capturing to avoid the deterioration of the food items within the fish gut. Fish gut analyses have been carried out under laboratory conditions. Morphological measures, frequency of occurrence and Index of fullness were calculated. The results indicated that C. ornata has established in the Attanagalu oya basin in areas such as Ekala and Kotugoda. Gut content analysis indicated that $C$. ornata feeds on significant number of native fish species. Five major prey fish species, consisting 58 Hirikanaya (Labeo dussumeri), 35 Rathu waral katu kuriya (Puntius kelumi), 23 Iri ankutta (Mystuss vittatus), 13 Walapoththa (Ompok bimaculatus) and 16 Illeya (Megalops cyprinoides) were found to make up the diet of 28 adults and 05 juveniles of $C$. ornata. The average Index of fullness was 378.19. Frequencies of occurrence are 0.606 , $0.485,0.424,0.121$ and 0.242 respectively for L.dussumeri, P. kelumi, M. vittatus, $O$. bimaculatus and $M$. cyprinoides. Out of these five species $P$. kelumi is listed as an endangered endemic species. Other than fishes, one shrimp species, molluscs and fish eggs were also recorded as their food items. Further, other exotic species such as Tank cleaner (Pterygoplichthys spp.) and giant gourami (Osphronemus goramy) were also recorded in the Attanagalu oya. It was concluded that immediate steps should be taken to manage this potentially harmful Alien invasive species in the Attanagalu Oya basin.
\end{abstract}

Keywords: Invasive, Exotic, Fresh water, Chitala, Attanagalu oya

Proceedings of the International Forestry and Environment Symposium 2016, Department of Forestry and Environmental Science, University of Sri Jayewardenepura, Sri Lanka. 